\title{
Effect of Thermocycling and Polyethylene Fibre Addition on Impact and Transversal Strength of Heat Cured Acrylic Resin Denture Base Material
}

\author{
Emerson Lim $^{1}$, Ismet Danial Nasution ${ }^{1}$,Indra Nasution ${ }^{2}$ \\ ${ }^{1}$ Department of Prosthodontics, Faculty of Dentistry, University of Sumatera Utara, Medan, Indonesia \\ ${ }^{2}$ Department of Science and Engineering, University of Sumatera Utara, Medan, Indonesia
}

\begin{abstract}
:
Background: Heat cured acrylic resin is the most widely used material in the manufacture ofdenture base, but has mechanical properties weakness (transversal strength and impact strength). Alternative to increase the mechanical properties of acrylic resin is the utilization of reinforcing fibre that is polyethylene fibre that has advantage such as good aesthetic, easy to manipulate and increase mechanical strength.

Purpose:This study was aimed to determine thermocycling effect on impact and transversal strength of heat cured acrylic resin denture base material without and with Ribbond THM and Ribbond Ultra polyethylene fibre addition, also to determine the effect of Ribbond THM and Ribbond Ultra fibre addition to impact and transversal strength of heat cured acrylic resin denture base material without and with thermocycling.

Material and Method: This is an experimental laboratory study. Samples for impact and transversal strength 30 samples each fabricated in Unit UJI Laboratorium Dental FKG USU. Thermocycling effect to impact and transversal strength of heat cured acrylic resin denture base material with and without polyethylene fibre addition was analyzed with $T$ test.The effect of polyethylene fibre addition to impact and transversal strength of heat cured acrylic resin denture base material without and with thermocycling analyzed with One Way ANOVA. LSD analysis then performed to see which polyethylene fibre has the best effect to impact and transversal strength of heat cured acrylic resin.

Result:The result showed there was thermocycling effect to impact strength value of heat cured acrylic resin denture base material without Ribbond THM and Ribbond Ultra fibre addition. There was thermocycling effect to transversal strength value of heat cured acrylic resin denture base material with Ribbond THM addition. There was an effect of polyethylene fibre addition to heat cured acrylic resin denture base material without and with thermocycling to impact and transversal strength.

Conclusion:Significant effect from impact and transversal strength of heat cured denture base material given Ribbond THM polyethylene fibre addition could still be accepted although there was decrease in the impact and transversal strength after thermocycling. Denture base given polyethylene fibre reinforcing material would increase its mechanical properties thus increasing the clinical utilization of heat cured acrylic denture.
\end{abstract}

Keywords:polyethylene fiber, thermocycling, impact strength, transversal strength

\section{Introduction}

Denture base is the part of denture which rest on soft tissue and to where artificial teeth are attached. The function of denture base is to replace missing alveolar bone, restore facial aesthetic, receive functional load and distribute functional load to supporting tissue, alveolar ridge or abutment teeth and support denture components. ${ }^{2,3}$ Ideal denture base material has to be biocompatible, non irritative, good dimension stability, bear mastication load, easy to manipulate, insoluble in saliva, good mechanical properties (modulus elasticity, transversal strength, impact strength, fatigue strength), good aesthetic, and easy to clean. ${ }^{1-7}$

Poly methyl methacrylate (acrylic resin/PMMA), first introduced as basic denture material in 1935, has been successfully used in restorative dentistry for the last 75 years and is the mostly used material in dentistry. ${ }^{8-}$

${ }^{11}$ Polymer denture base material classification according to ISO (20795-1:2013(E)) divided into 5 types such as type 1 (heat processing polymers), type 2 (auto polymerized polymers), type 3 (thermoplastic blank or powder), type 4 (light activated materials) dan type 5 (microwave cured materials).

The advantages of acrylic resin are good biocompatibility, easy manipulation process, good endurance on food and organic fluid, good aesthetic, low price, and stable in oral cavity. ${ }^{10,13-17}$ Although it has a lot of advantages, acrylic resin has very weak mechanical resistance. ${ }^{8-11}$ Denture base fracture is the result of denture mechanical properties weakness which is impact strength and transversal strength., ${ }^{8,14}, 17-19$ The weakness of impact strength caused by sudden stress like dropping denture on hard surface. ${ }^{19,20}$ A study by Johnston et al. showed that $68 \%$ of acrylic resin denture manufacture broke in a few years mainly because of impact strength. ${ }^{21}$ The weakness of transversal strength happen because of denture base tense while mastication which trigger crack. $^{11,16,17,20}$ 
For years, lots of effort has been done to increase the mechanical properties of acrylic resin. Conventional method used to strengthen denture base polymer commonly using metal wire or plate. The effect of metal addition is minor. ${ }^{8,14,16,17}$ The main problem of this method is low adhesion between metal wire or plate to acrylic resin, expensive, corrosive and not aesthetic. ${ }^{14,17,19,20}$ Addition to denture thickness is also an effort to increase acrylic resin denture strength. ${ }^{20}$ Several study has been done to overcome acrylicresin weakness such as addition of reinforcing material to acrylic denture base material intended to increase mechanical properties of acrylic resin such as fracture resistance, mastication load and overtime utilization. Other way to increase mechanical properties of acrylic denture is to add fibre into denture basic polymer. ${ }^{16-18}$ A few fibre types reported can increase mechanical properties such as glass, polyethylene, silica, polycarbonate, carbon (graphite), sapphire, ceramic, nylon, and aramyde (polyamides polyaromatic). ${ }^{8,9,11,20,21}$

The most commonly used fibre as acrylic resin denture base reinforcing material is polyethylene fibre. Polyethlylene fibre has several profitable properties such as easy to manipulate, biocompatible, natural colours, bond well with resin matrix and good aesthetic. ${ }^{8}$ UHMWPE polyethylene fibre commonly used as composite reinforcing fibre is fibre reinforced fibre resin based material to increase physical properties. ${ }^{22}$ Ribbond polyethylene fibre was one of UHMWPE polyethylene fibre introduced in 1992 in dentistry and was reinforced polyethylene fibre reinforcing material which was easy to manipulate. The fibre has breaking point beyond glass fibre and require special scissor to cut. The main success key from Ribbond polyethylene fibre is lenoweave webbing patented with lock-stitch design which has effectiveness to transfer load pass webbing without reverse pressure to resin. The characteristics of Ribbond polyethylene are translucent, colorless between composite or acrylic resulting in maximum aesthetic. The application of this fibre in dentistry also useful as endodontic post, periodontal splint, aesthetic space maintainer, single unit crown and orthodontic retainer. ${ }^{22}$

\section{Material And Method}

This is an experimental laboratory study. Samples for impact and transversal strength 30 samples each fabricated in Unit UJI Laboratorium Dental FKG USU. Test group were divided into 12 groups: control group impact strength test without addition of fibre and without thermocycling (A), impact strength test group with Ribbond THM polyethylene fibre and without thermocycling (B), impact strength test group with Ribbond Ultra polyethylene fibre and without thermocycling $(\mathrm{C})$, control group transversal strength test without addition of fibre and without thermocycling (D), transversal strength test group with Ribbond THM polyethylene fibre and without thermocycling (E), transversal strength test group with Ribbond Ultra polyethylene fibre and without thermocycling $(F)$, control group impact strength test without addition of fibre and with thermocycling $(G)$, impact strength test group with Ribbond THM polyethylene fibre and with thermocycling $(\mathrm{H})$ impact strength test group with Ribbond Ultra polyethylene fibre and with thermocycling (I), control group transversal strength test without addition of fibre and with thermocycling $(\mathrm{J})$, transversal strength test group with Ribbond THM polyethylene fibre and with thermocycling $(\mathrm{K})$, transversal strength test group with Ribbond Ultra polyethylene fibre and with thermocycling (L).

Impact strength test samples were fabricated in $80 \mathrm{~mm}$ x $10 \mathrm{~mm}$ x $4 \mathrm{~mm}$ size (ISO 179-1:2000). ${ }^{20}$ Transversal strength test samples were fabricated in $65 \mathrm{~mm}$ x 10mm x 3,3mm (ISO 20795-1:2013(E)). Samples with addition of THM and Ultra Ribbond polyethylene fibre were cut with special scissors in accordance with the sample length, $65 \mathrm{~mm}$ for transversal samples and $80 \mathrm{~mm}$ for impact samples soaked in monomer for 3 minutes inside a container and then drained. After the mix reached dough stage, it was inserted into mold. The polymer and monomer mix was divided into 2 parts (upper cuvet and lower cuvet). Heat cured acrylic resin was pressed in advance and separated by using transparent plastic then the upper cuvet installed and the cuvet was pressed with 1000psi hydrolic press, then the upper cuvet opened and the excess acrylic was cleaned by using lecron. Ribbond THM polyethylene fibre after drained was placed in the middle of polymer and monomer mix by tweezers. Upper cuvet was placed back and hydrolic press with 2200 psi pressure was applied. The cuvet bolt was installed to maintain good adaptation between upper and lower cuvet, then left it for 30 minutes. Cuvet inserted in the water at $70^{\circ} \mathrm{Cand}$ heated above waterbath for 90 minutes (phase I). The temperature of cuvet was kept constant at $100^{\circ} \mathrm{C}$ and left for 30 minutes (phase II). Cuvet was left until room temperature for cooling process. Sample taken out from the cuvet, then the excess acrylic was cut out and trimmed with frasser bur and the rough part polished by using waterproof sand paper no. 600, 800, 1000 and 1200 which was installed on rotary grinder with flowing water for 3 minutes each with the speed 500rpm, then continued by Scotch-Brite brush which was installed on polishing motor with the speed 500rpm and using coarce pumice until shiny. Then sample was soaked in aquadest with temperature $37^{\circ} \mathrm{C}$ for 50 hours inside incubator (ISO 3696:1987). ${ }^{12,23}$

Impact strength test performed with impact strength test device Charpy Impact Tester (TIME, small pendulum, 0-150J, China). Sample was numbered on both end, then positioned horizontal resting on both end of the tester, then beater arm on the tester was locked, then the beater arm's lock was released until hitting the sample to break. Energy showed on the tester was read and noted and impact strength calculation was performed $\left(\mathrm{KJ} / \mathrm{m}^{2}\right)$. Transversal strength test was performed with transversal strength tester 3-point-bending test machine 
(Shimadzu EZ-S 500N, Japan). Sample was numbered on both end, then positioned with horizontal position resting on both end of the testerwith $5 \mathrm{~cm}$ range. Then crosshead pressure $(5 \mathrm{~mm} / \mathrm{minute}$ speed) was applied to the middle part of the sample starting from deflected sample so the sample look fractured. Energy showed on the tester was read and noted and transversal strength calculation was performed (MPa).

The effect of thermocycling to impact and transversal strength of heat cured acrylic resin denture base material with and without Ribbond THM and Ribond Ultra polyethylene fibre addition analyzed with T test. The effect of Ribbond THM and Ribbond Ultra fibre addition to impact and transversal strength of heat cured acrylic resin denture base material without and with thermocycling analyzed with One Way ANOVA. LSD analysis then performed to see which Ribbond polyethylene fibre has the best effect to impact and transversal strength of heat cured acrylic resin.

\section{Result}

$\mathrm{T}$ test result showed significant difference of impact strength test group value without polyethylene fibre addition without thermocycling and with thermocycling with $p=0,048(\mathrm{p}<0,05)$, then there was a significant thermocycling effect statistically on impact strength test group without the addition of polyethylene fibre on heat cured resin acrylic denture base without fibre addition (Table 4.1). $T$ test result showed that there was insignificant difference on impact strength test group value with Ribbond THM polyethylene fibre addition and with thermocycling with $\mathrm{p}=0,508(\mathrm{p}<0,05)$, then there was no thermocycling effect statistically on impact strength test group on resin heat cured acrylic resin denture base material with the addition of Ribbond THM polyethylene fibre (Table 4.1). T test result showed there was insignificant difference of impact strength test group value with Ribbond Ultra polyethylene fibre addition without thermocycling and with thermocycling with $\mathrm{p}=0,728(\mathrm{p}<0,05)$, then there was no thermocycling effect statistically on impact strength test group of heat cured acrylic resin denture base material with Ribbond Ultra polyethylene fibre addition (Table 4.1).

Table 4.1 Impact strength test value of heat cured acrylic resin denture base material without and with Ribbond THM and Ribbond Ultra polyethylene fibre addition

Note: * : Significant $(\mathrm{p}<0,05)$

\begin{tabular}{|c|c|c|c|c|}
\hline \multirow[b]{2}{*}{ Group } & \multirow[b]{2}{*}{$\mathrm{n}$} & \multicolumn{2}{|c|}{ Impact Strength $\left(\mathrm{KJ} / \mathrm{m}^{2}\right)$} & \multirow[b]{2}{*}{$\mathrm{P}$} \\
\hline & & WithoutThermocycling & $\begin{array}{c}\text { With } \\
\text { Thermocycling }\end{array}$ & \\
\hline $\begin{array}{c}\text { Without } \\
\text { polyethylene } \\
\text { fibre } \\
\text { addition }\end{array}$ & 4 & $35,8 \pm 0,5597$ & $35,1 \pm 0,0817$ & $0,048^{*}$ \\
\hline $\begin{array}{c}\text { Ribbond } \\
\text { THM } \\
\text { polyethylene } \\
\text { fibre } \\
\end{array}$ & 4 & $39,22 \pm 0,741$ & $38,87 \pm 0,6652$ & 0,508 \\
\hline $\begin{array}{c}\text { Ribbond } \\
\text { Ultra } \\
\text { polyethylene } \\
\text { fibre }\end{array}$ & 4 & $37,5 \pm 1,7378$ & $37,15 \pm 0,81$ & 0,728 \\
\hline
\end{tabular}

$\mathrm{T}$ test result showed significant difference in transversal strength test group value without polyethylene fibre addition without thermocycling and with thermocycling with $p=0.872(p<0.05)$, then there was no significant thermocycling effect statistically on transversal strength test groupwithout polyethylene fibre addition on acrylic resin denture base material. $T$ test result showed there was insignificant difference transversal strength test group value with Ribbond THM polyethylene fibre addition without thermocycling and with thermocycling with $\mathrm{p}=0.031(\mathrm{p}<0.05)$, then there was significant thermocycling effect on transversal strength test group of heat cured acrylic resin denture base material with Ribbond THM polyethylene fibre addition (Table 4.2). T test result showed that there was insignificant transversal strength test group valuewith Ribbond Ultra polyethylene fibre addition without thermocyling and with thermocycling with $\mathrm{p}=0.145(\mathrm{p}<$ $0.05)$, then there was no thermocycling effect statistically on transversal strength test group of heat cured acrylic resin denture base material with Ribbond Ultra polyethylene fibre addition (Table 4.2). 
Table 4.2 Transversal strength test value of heat cured acrylic resin denture base material without and with Ribbond THM and Ribbond Ultra polyethylene fibre addition

Note $: *$ : Significant $(\mathrm{p}<0,05)$

\begin{tabular}{|c|c|c|c|c|}
\hline \multirow{2}{*}{ Group } & \multirow{2}{*}{$\mathrm{n}$} & \multicolumn{2}{|c|}{ Tranvsersal Strength (MPa) } & \multirow{2}{*}{$\mathrm{p}$} \\
\cline { 3 - 4 } & & $\begin{array}{c}\text { Without } \\
\text { Thermocycling }\end{array}$ & $\begin{array}{c}\text { With } \\
\text { Thermocycling }\end{array}$ & \\
\hline $\begin{array}{c}\text { Without } \\
\text { polyethylene } \\
\text { fibre } \\
\text { addition }\end{array}$ & 4 & & & \\
\hline $\begin{array}{c}\text { Ribbond } \\
\text { THM } \\
\text { polyethylene } \\
\text { fibre }\end{array}$ & 4 & $70,36 \pm 3,5994$ & $69,67 \pm 1,9402$ & 0,872 \\
\hline $\begin{array}{c}\text { Ribbond } \\
\text { Ultra } \\
\text { polyethylene } \\
\text { fibre }\end{array}$ & 4 & $88,53 \pm 1,6128$ & $83,15 \pm 0,9361$ & $0,031^{*}$ \\
\hline
\end{tabular}

Table 4.3 Transversal strength test value of heat cured acrylic resin denture base material without and with Ribbond THM and Ribbond Ultra polyethylene fibre addition

\begin{tabular}{|c|c|c|c|}
\hline \multirow[b]{2}{*}{ Group } & \multirow[b]{2}{*}{ Sample Number } & \multicolumn{2}{|c|}{ Transversal Strength (MPa) } \\
\hline & & Without thermocycling & $\begin{array}{c}\text { With } \\
\text { Thermocycling }\end{array}$ \\
\hline \multirow{5}{*}{$\begin{array}{c}\text { Without } \\
\text { polyethylene fibre } \\
\text { addition }\end{array}$} & 1 & $61,35^{*}$ & $73,39 * *$ \\
\hline & 2 & 74,56 & 71,85 \\
\hline & 3 & $77,51 * *$ & $64,58 *$ \\
\hline & 4 & 68,01 & 68,85 \\
\hline & $\begin{array}{c}\text { average } \\
\text { (standard deviation) }\end{array}$ & $70,36 \pm 3,5994$ & $69,67 \pm 1,9402$ \\
\hline \multirow{5}{*}{$\begin{array}{l}\text { Ribbond THM } \\
\text { polyethylene fibre }\end{array}$} & 1 & 90,61 & $81,51 *$ \\
\hline & 2 & $83,96^{*}$ & 82,95 \\
\hline & 3 & $93 * *$ & $85,82 * *$ \\
\hline & 4 & 89,12 & 82,34 \\
\hline & $\begin{array}{c}\text { Average } \\
\text { (standard deviation) }\end{array}$ & $88,53 \pm 1,6128$ & $83,15 \pm 0,9361$ \\
\hline \multirow{5}{*}{$\begin{array}{l}\text { Ribbond Ultra } \\
\text { polyethylene fibre }\end{array}$} & 1 & $99,28 * *$ & $68,68 *$ \\
\hline & 2 & 76,1 & 70,91 \\
\hline & 3 & $71,70 *$ & 70,55 \\
\hline & 4 & 84,78 & $78,5 * *$ \\
\hline & $\begin{array}{c}\text { average } \\
\text { (standard deviation) }\end{array}$ & $82,96 \pm 6,079$ & $72,16 \pm 2,1699$ \\
\hline
\end{tabular}

Note :* : smallest value ** : largest value

Table 4.4 Transversal strength test value of heat cured acrylic resin denture base material without and with Ribbond THM and Ribbond Ultra polyethylene fibre addition

Note : $*$ : Significant $(\mathrm{p}<0,05)$

\begin{tabular}{|c|c|c|c|c|}
\hline \multicolumn{1}{c}{ Ribbond THM and Ribbond Ultra polyethylene fibre addition } \\
\hline & $\mathrm{n}$ & \multicolumn{2}{|c|}{ Tranvsersal Strength (MPa) } & \multirow{2}{*}{$\mathrm{p}$} \\
\cline { 3 - 4 } & & Without thermocycling & With Thermocycling & \\
\hline $\begin{array}{c}\text { Without polyethylene } \\
\text { fibre addition }\end{array}$ & 4 & $70,36 \pm 3,5994$ & $69,67 \pm 1,9402$ & 0,872 \\
\hline $\begin{array}{c}\text { Ribbond THM } \\
\text { polyethylene fibre }\end{array}$ & 4 & $88,53 \pm 1,6128$ & $83,15 \pm 0,9361$ & $0,031^{*}$ \\
\hline $\begin{array}{c}\text { Ribbond Ultra } \\
\text { polyethylene fibre }\end{array}$ & 4 & $82,96 \pm 6,079$ & $72,16 \pm 2,1699$ & 0,145 \\
\hline
\end{tabular}

Table 4.5 The effect of Ribbond THM and Ribbond Ultra polyethylene fibre addition to impact strength of heat cured acrylic resin denture base material without thermocycling 


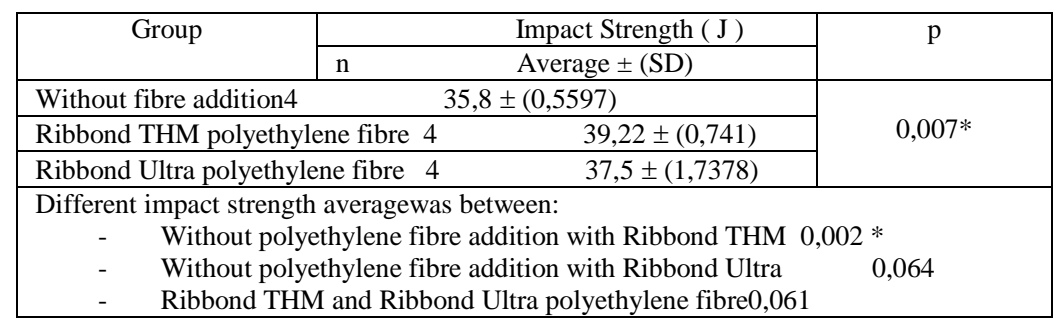

Note : $*$ Significant $(\mathrm{p}<0,05)$

Table 4.6 The effect of Ribbond THM and Ribbond Ultra polyethylene fibre addition to impact strength of heat cured acrylic resin denture base material with thermocycling

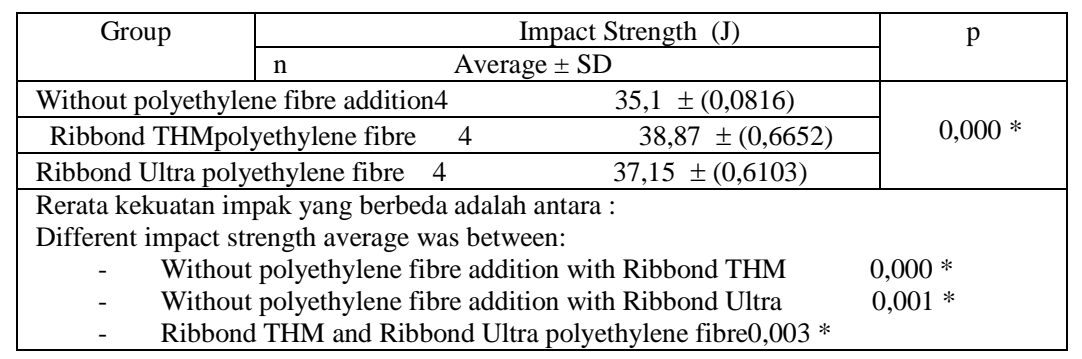

Note : * : Significant $(\mathrm{p}<0,05)$

Result showed that there was thermocycling effect to impact strength value heat cured acrylic resin denture base material without Ribbond THM and Ribbond Ultra fibre addition. There was no thermocycling effect to impact strength value of heat cured acrylic resin denture base material with Ribbond THM fibre addition. There was thermocycling effect to transversal strength of heat cured acrylic resin denture base material with Ribbond THM addition. There was no thermocycling effect to transversal strength of heat cured acrylic resin denture base material without fibre addition and with Ribbond Ultra fibre addition. There was polyethylene fibre addition effect of heat cured acrylic resin denture base material without and with thermocycling to impact strength value.Average value of Ribbond THM showed the most significant impact strength after thermocycling with the value at $38.875 \pm 0.6652 \mathrm{KJ} / \mathrm{m}^{2}(\mathrm{p}$ value $=0.000)$ and highest transversal strength $83.15 \pm 0.9361 \mathrm{MPa}(\mathrm{p}$ value $=0.000)$.

\section{Discussion}

Result showed that there was significant decrease in mechanical strength mainly from impact strength value of heat-cured acrylic resin without the addition of fibre as a result of thermocycling process. This was caused by the effect of water sorption enabling water molecules to penetrate to the area between polymer chain and act as incision between chains. Water enter the polymer material during submersion mainly caused by diffusion, and partially polymer chain polarity caused by unsaturated molecules and imbalance intermolecular forces. ${ }^{11,13}$ Water molecule penetration cause denture base softening, as absorbed water can act like polymethyl methacrylate plasticizer. Water sorption reduce material's mechanical properties in case of impact strength. ${ }^{8,9,11,13,24}$

Result showed the effect of thermocycling to decrease of transversal strength value from every sample became lower caused by base plasticizer. Thermocycling was a standard in vitro method used to evaluate mechanical and physical properties of a restorative or prosthetic material experiencing aging by simulating oral cavity. ${ }^{25,26}$ Thermocycling process resulted in hydration process in accordance with clinical condition, therefore resin absorb water and break the bond. Water absorbed directly could break the bond because of void presence between layers.

Result showed the effect of Ribbond THM and Ribbond Ultra polyethylene fibre addition showed increase of impact strength value more significant from control group. The effect of Ribbond THM polyethylene fibre showed the highest strength value on the group with and without thermocycling. This was caused by Ribbond THM polyethylene fibre was thicker than Ribbond Ultra polyethylene fibre, so that the adhesion was more maximum. This was caused by adhesion between Ribbond THM polyethylene fibre and resin more maximum compare to Ribbond Ultra polyethylene fibre.Sample fragment showed resin reinforced with Ribbond Ultra polyethylene fibre showed bigger voids than Ribbond THM polyethylene fibre. The similar study wasalso 
conducted by Lasilla et al (2002) stated thatfibres with smaller diameter could easily cause voids between fibre surface and matrix thus decreasing mechanical properties and modulus elasticity. ${ }^{27}$

Results showed there was an effect of Ribbond THM polyethylene fibre to transversal strength showed highest strength compare to other groups. This showed that small diameter fibre not necessarily showed higher transversal strength increase. Smaller diameter fibre increased better modulus elasticity than other groups. In this study, modulus elasticity increase $45 \%$ from control group on Ribbond Ultra polyethylene fibre addition compare to $18 \%$ increase from control group on Ribbond THM polyethylene fibre. Higher modulus elasticity caused denture base material to be more rigid. This could cause decrease of transversal strength. This study corresponded to the study by Watri D (2011) who stated the rigidity of fibre material affecting flexibility of material thus could weaken the transversal strength. Lack of impregnation of the fibre that would be inserted in the matrix caused porosity that could cause water $\operatorname{sorption}^{8,28}$ and also reducing the transversal strength of denture base. $^{29}$

\section{Conclusion}

Thermocycling which is done to simulate heat cured acrylic denture base material as used in oral cavity for 3 years gave effect of impact and transversal strength decrease. The addition of Ribbond polyethylene fibre has a role in increasing the impact and transversal strength to overcome the mechanical weakness. The addition of Ribbond THM polyethylene fibre showed significant increase after thermocycling from the impact and transversal strength. Significant effect from impact and transversal strength of heat cured denture base material given Ribbond THM polyethylene fibre addition could still be accepted although there was decrease in the impact and transversal strength after thermocycling. Denture base given polyethylene fibre reinforcing material would increase its mechanical properties thus increasing the clinical utilization of heat cured acrylic denture.

\section{References}

[1]. McCabe JF., Walls AWG. Applied dental materials. Edisi 9. London: Blackwell Munksgaard. 2007: 110-23.

[2]. Gunadi A. Ilmu geligi tiruan sebagian lepasan. Jakarta: Hipokrates, 2012: 215-220.

[3]. Mc.Cracken's., Removable Partial Prosthodontics. Edisi 10. CV. Mosby Company. $2000: 127$.

[4]. Zarb, et al. Prosthodontic treatment for edentulous patients. 13th. Elsevier: Singapore, 2012: 133-141.

[5]. Schricker SR, et al. Effect of methacrylated hyperbranched polymers on the fracture properties of denture base materials. Journal of Macromolecular Science 2006; 43:205-12.

[6]. Tandon R, Gupta S, Agarwal SK. Denture base materials: from past to future. Indian Journal of Dental Sciences 2010 March, 2(2): 33-39.

[7]. Chhnoeum T. Effect of denture cleanser on the surface roughness and hardness of denture base material. Thesis. Mahidol University. $2008: 8-15$.

[8]. Raszewski Z, Nowakowska D. Mechanical properties of hot curing acrylic resin after reinforced with different kinds of fibers. International Journal of Biomedical Materials Research 2013; 1(1): 9-13.

[9]. Raszewski Z, Nowakowska D. Mechanical properties of poured aramid fiber reinforced acrylic resin depending on fiber quantity, fiber position and different wetting agents. Dent. Med. Probl. 2011; 48 (3): 380-7.

[10]. Hamza T, Wee AG, Alapati S, Schricker SR. The fracture toughness of denture base material reinforced with different concentrations of poss. Journal of Macromolecular Science 2004; 41(8): 897-906.

[11]. Vojvodić D, Komar D, Schauper Z, Čelebić A, Mehulić K, Žabarović D. Influence of different glass fiber reinforcements on denture base polymer strength (fiber reinforcements of dental polymer). Medicinski Glasnik. 2009; 6 (2): $227-33$.

[12]. International Standart., 2013. Dentistry- base polymers- part 1: denture base polymers. ISO 20795-1: 1-31

[13]. Yöndem I, Yücel M, Aykent F, Öztürk AN. Flexural strength of denture base resin reinforced with different fibers.SÜ Dişhek Fak Derg, 2011; 20:15-20.

[14]. Vojdani M, Khaledi AAR . Transverse strength of reinforced denture base resin with metal wire and e-glass fibers. Journal of Dentistry, Tehran University of Medical Science. 2006; 3 (4): 167-172.

[15]. Maldonado VM, Torres LSA, Santana FHB, Lancon RDV, Rodriguez MEP, Castano VM. Fiber-reinforced nanopigmented poly (methyl methacrylate) as improved denture base. Journal of Applied Polymer Science, 2012; 000: 1-8.

[16]. Narva KK, Lassila LV, Vallittu PK. The static strength and modulus of fiber reinforced denture base polymer. Academy of Dental Materials Elsevier 2005; 21: 421-8.

[17]. Yu HS, Lee Y, Oh S, Cho WH, Oda Y, Bae MJ. Reinforcing effects of different fibers on denture base resin based on the fiber type, concentration, and combination.Dental Materials Journal 2012; 31(6): 1039-46.

[18]. Unalan F, Dikbas I, Gurbuz O. Transverse strength of polymethylmethacrylate reinforced with different forms and concentrations of e-glass fibres. OHDMBSC 2010; 9(3):144-7.

[19]. Jagger DC, Harrison A, Jandt KD. Review- the reinforcement of dentures. Journal of Oral Rehabilitation1999; 26:185-194.

[20]. Bashi TK, Al-Nema LM. Evaluation of some mechanical properties of reinforced acrylic resin denture base material (an in vitro study). Al-Rafidain Dent J. 2009; 9(1): 57-65.

[21]. Mowade TK, Dange SP, Thakre MB, Kamble VD. Effect of fiber reinforcement on impact strength of heat polymerized polymethyl methacrylate denture base resin: in vitro study and SEM analysis. J Adv Prosthodont 2012; 4:30-6.

[22]. Ganesh M, Tandon S. Versatility of ribbond in contemporary dental practice. Trends Biomater. Artif. Organs 2006; 20(1): 53-8.

[23]. Rahamneh A.Impact strength of acrylic resin denture base material after the addition of different fibres. Pakistan Oral \& Dental Journal 2009; 29 (1):181-4.

[24]. Paladugu LS, Sivakumar M, Ganta R. Evaluation of flexural strength, impact strength and water sorption of various denture base resins- an in vitro study. J Res Adv Dent 2014; 3(2s): 94-9.

[25]. Goiato MC, Zuccolotti BCR, Santos DM, Moreno A, Alves-Rezende MCR. Effects of thermocycling on mechanical properties of soft lining materials. Acta Odontol. Latinoam 2009; 22(3): 227-32. 
[26]. Mancuso DN, Goiato MC, Zuccolotti BCR, Moreno A, Santos DM, Pesqueira AA. Effect of thermocycling on hardness, absorption solubility and colour change of soft liners. The Gerondontology Society and John Wiley and Sons 2012; 29: e215-9.

[27]. Rezvani MB, Atai M, Hamze F. Effect of fiber diameter on flexural properties of fiber-reinforced composites. Indian Journal of Dental Research 2013; 24(2): 237-41.

[28]. Lončar A, Vojvodić D, Jerolimov V, Komar D, Žabarović D. Fiber reinforced polymers part II: effect on mechanical properties. Acta Stomatol Croat. 2008;42(1):49-63.

[29]. Kanie T., Fujii K., Arikawa H., Inoue K. Flexural properties and impact strength of denture base polymer reinforced with woven glass fibers. Dental Materials 2000; 16:150-8. 